\title{
Use of Oral Erythromycin for the Treatment of Gastrointestinal Dysmotility in Preterm Infants
}

\author{
Pak C. Ng \\ Department of Paediatrics, Prince of Wales Hospital, The Chinese University of Hong Kong, Hong Kong, SAR, China
}

\section{Key Words}

Erythromycin • Gastrointestinal dysmotility • Preterm infants

\begin{abstract}
Milk intolerance due to functional gastrointestinal (GI) dysmotility is a common problem in preterm infants. In the past decade, erythromycin has been used for its motilinomimetric effect to facilitate enteral feeding in preterm infants. Although earlier studies suggested that erythromycin is an effective prokinetic agent, recent randomized control trials (RCTs) reveal conflicting findings. This review assesses the evidence from all RCTs performed to date on erythromycin for preterm infants. The results suggest that oral erythromycin administered in intermediate or high doses as a rescue treatment is associated with a shorter time to attain full enteral feeding and decrease in the duration of requirement for parenteral nutrition. More importantly, the outcome study further indicates that oral erythromycin can reduce the incidence of parenteral nutrition-associated cholestasis by almost 50\% and decreases the incidence of recurrent septicemia. None of the RCTs reported any sinister adverse effects, in particular, hypertrophic infantile pyloric stenosis or fatal cardiac arrhythmia. Nonetheless, as long-term outcomes have not been fully evaluated, neonatologists should use this treatment cautiously and selectively in preterm infants with moderately severe GI dysmotility.
\end{abstract}

Copyright $\odot 2008$ S. Karger AG, Basel

\section{Introduction}

Functional or nonobstructive gastrointestinal (GI) dysmotility associated with milk intolerance is a common condition in preterm, very low birth weight (VLBW) infants $[1,2]$. It is characterized by protracted feeding intolerance with increased gastric residuals, intermittent regurgitation or vomiting and in severe cases gross abdominal distension. In contrast to necrotizing enterocolitis (NEC) and isolated GI perforation secondary to postnatal corticosteroids and prostaglandin inhibitors [3-5], bloody stool, abdominal erythema and signs and symptoms suggestive of peritonitis are typically absent. Abdominal radiograph shows generalized bowel distension but with no pneumatosis intestinalis or free gas in the abdominal cavity (fig. 1). Biomarkers of infection, including serial serum C-reactive protein and neutrophil CD64 levels are not raised [6]. The abdomen decompresses readily $24-48 \mathrm{~h}$ after stopping milk feeds but the situation often recurs during reintroduction of enteral feeding. This clinical entity is believed to be the consequence of infrequent, ineffective and uncoordinated bowel activity secondary to immaturity of the GI tract $[1,2]$. Although GI dysmotility of prematurity per se is a relatively benign condition, the fear of NEC and other sinister intra-abdominal patholo-

Presented at the International Symposium 'Recent Advances in Neonatal Medicine', Würzburg, 2008.

\section{KARGER}

Fax +41613061234 E-Mail karger@karger.ch www.karger.com
Prof. Pak C. Ng

Department of Paediatrics, Level 6, Clinical Sciences Building

Prince of Wales Hospital, The Chinese University of Hong Kong

Shatin, N.T., Hong Kong, SAR (China)

Tel. +852 2632 2851, Fax +852 2636 0020, E-Mail pakcheungng@cuhk.edu.hk 


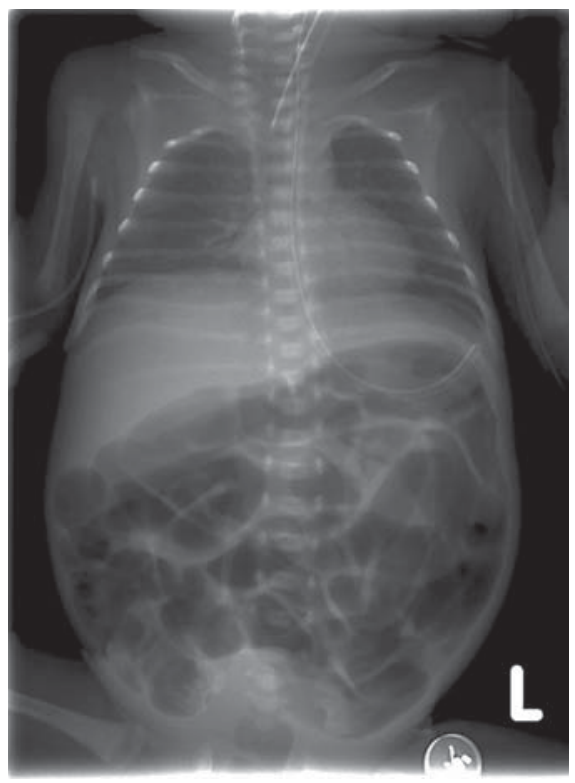

Fig. 1. An abdominal radiograph of a preterm infant with severe functional gastrointestinal dysmotility who suffered from protracted feeding intolerance and repeated abdominal distension. There are generalized, thin-walled, distended bowel loops but without evidence of necrotizing enterocolitis. The diaphragm is splinted upwards and the infant required positive pressure ventilation despite the fact that he did not have chronic lung disease. A percutaneous line is inserted in the right arm for parenteral nutrition. There are radiologic features suggestive of rickets at the metaphyses of long bones.

gies frequently results in stoppage of feeding and prolonged hyperalimentation. Long-term parenteral nutrition has been associated with increased risks of serious morbidity and sometimes even life-threatening complications, including parenteral nutrition-associated cholestasis (PNAC) [1,2], recurrent catheter-related septicemia [7, 8], nutritional deficiency, biochemical rickets, and pain and anesthetic risks associated with repeated percutaneous and central long line insertions [9]. Thus, prokinetic agents that can enhance GI motility may be potentially beneficial to preterm infants, who fail to establish full enteral feeding after a prolonged period and in whom a structural lesion of the GI tract has been excluded, by promoting milk feeding and reducing the duration of parenteral nutrition and its associated adverse effects.

Erythromycin, a commonly used macrolide and antibiotic, has been found to possess potent prokinetic properties and has been used in older children and adults for treatment of gastroparesis due to diabetes mellitus, scleroderma or following esophagectomy and vagotomy [9]. Its motilin agonistic action has also been clinically exploited for the management of a variety of GI dysmotility disorders, including: gastro-esophageal reflux, chronic functional pseudo-obstruction and postoperative intestinal ileus [9]. Further, erythromycin has been used successfully in facilitating transpyloric passage of endoscopes, Watson's capsules and nasoenteric feeding tubes into the proximal small bowel [9]. Although the role of erythromycin as a prokinetic agent in preterm, VLBW infants has been recently investigated in a number of randomized control trials (RCTs) [10-19], much controversy concerning its efficacy in promoting enteral feeding and adverse effects remain. This review summarizes the results of recent RCTs in order to explore whether collectively, a common message may emerge so that indications for erythromycin usage and practical guidelines for this medication may be established and gauged according to the prevailing evidence.

\section{Review of RCTs}

Systematic literature search for RCTs concerning erythromycin use, at any dose, intravenous or oral, in preterm infants to facilitate GI motility were identified by searching through MEDLINE, EMBASE and abstracts published in Pediatric Research. To date, 10 RCTs have reported effects of erythromycin on preterm newborns [10-19]. Seven RCTs used erythromycin as a rescue treatment [13-19] and 3 studies used the medication as a prophylactic prokinetic agent [10-12]. The characteristics of the study populations and findings of these RCTs are summarized in tables 1 and 2. The 2 RCTs reported by The Cochrane Database of Systemic Review [20] are included in the current analysis.

Of the 3 prophylactic RCTs (table 1) [10-12], 2 studies did not demonstrate any benefit of erythromycin as an effective prokinetic agent $[10,11]$. In addition, the objective of the RCT by Stenson et al. [10] primarily concerned the use of intravenous erythromycin for eradication of Ureaplasma urealyticum and prevention of chronic lung disease. Their investigation on the effect of erythromycin in enteral feeding was a secondary data analysis. Thus, the study was not originally designed nor intended to answer the question on feeding intolerance. In this category of RCTs, only the study by Oei and Lui [12] suggested that the use of oral erythromycin was associated with significantly fewer episodes of large residual gastric aspirates and treated infants were able to attain full enteral feeding more rapidly. On the whole, prophylactic studies [10-12] 
Table 1. RCTs of erythromycin as a prophylactic prokinetic agent in preterm infants

\begin{tabular}{|c|c|c|c|}
\hline & Stenson et al. [10] & Patole et al. [11] & Oei et al. [12] \\
\hline Purpose & prophylaxis & prophylaxis & prophylaxis \\
\hline Sample size & 76 & 73 & 43 \\
\hline Inclusion criteria & ventilated infants $<31$ weeks' gestation & $<32$ weeks' gestation & $\leq 32$ weeks' gestation \\
\hline Exclusion criteria & major congenital abnormalities & $\begin{array}{l}\text { major congenital anomalies and } \\
\text { chromosomal aberrations }\end{array}$ & $\begin{array}{l}\text { major congenital malformation; } \\
\text { perinatal hypoxia (Apgar score } \\
<5 \text { at } 5 \text { min); other conditions: } \\
\text { intraventricular hemorrhage } \\
\text { (>grade 1), sepsis, NEC, organic } \\
\text { abdominal pathologies }\end{array}$ \\
\hline \multicolumn{4}{|l|}{ Erythromycin usage } \\
\hline Dosage & high dose ( $15 \mathrm{mg} / \mathrm{kg}$ every $8 \mathrm{~h})$ & high dose (12 mg/kg every $6 \mathrm{~h})$ & low dose ( $2.5 \mathrm{mg} / \mathrm{kg}$ every $6 \mathrm{~h})$ \\
\hline Duration, days & 7 & until full enteral feeding or 14 & 10 \\
\hline Route of administration & intravenous & oral & oral \\
\hline \multicolumn{4}{|l|}{ Results } \\
\hline $\begin{array}{l}\text { Age achieved full enteral feeding } \\
\text { after treatment: erythromycin vs. } \\
\text { placebo, days }\end{array}$ & $8(5-12)$ vs. $9(6-14)^{*}$ & $3.9(3.4-5.9)$ vs. $4.3(3.4-6.8)^{* *}$ & $6.0 \pm 2.3$ vs. $7.9 \pm 3.5$ \\
\hline Findings & no benefit & no benefit & facilitated enteral feeding \\
\hline Adverse effects & nil & insignificant elevation of theophylline level & nil \\
\hline Comments & $\begin{array}{l}\text { - primary objective of this study was } \\
\text { the prevention of chronic lung } \\
\text { disease by eradication of Ureaplasma } \\
\text { urealyticum }\end{array}$ & $\begin{array}{l}\text { - sample size inadequate to detect }<30 \% \\
\text { improvement in outcome } \\
\text { - time to establish full enteral feeding in all } \\
\text { enrolled infants was reduced by }>50 \%\end{array}$ & - nil \\
\hline
\end{tabular}

Results are * median (range), ${ }^{* *}$ median (interquartile range) or mean $( \pm \mathrm{SD})$.

None of the studies reported an increase in incidence of adverse effects associated with the use of erythromycin, including infantile hypertrophic pyloric stenosis, cardiac dysrhythmia, sepsis and NEC.

suffer the prejudice of indiscriminately treating all infants and do not specifically target those who are most in need of prokinetic treatment. Thus, prophylactic RCTs may not necessarily reveal the full potential of erythromycin in facilitating enteral feeding. Further, as this agent has bacteriostatic properties, neonatologists would be most reluctant to prescribe the medication routinely due to worries of promoting emergence of multidrug-resistant organisms and alteration of microbiologic flora in the GI tract at such an early stage in life.

Seven RCTs used erythromycin as a rescue treatment for preterm infants with feeding intolerance (table 2) [1319]. Four clinical trials used low doses $(3-15 \mathrm{mg} / \mathrm{kg} / \mathrm{day}$ administered either orally or intravenously) [13-16], whereas the other 3 trials used either an intermediate/ high dose tapering regimen $(40 \mathrm{mg} / \mathrm{kg}$ for 2 days followed by $16 \mathrm{mg} / \mathrm{kg}$ for 5 days) [17] or high doses (50 mg/day) [18, 19]. It is worth noting that all patients in the 'pilot' study by $\mathrm{Ng}$ et al. [18] were included in the final analysis of their 'outcome' study [19]. Three of the 4 RCTs using a lowdose regimen did not show any beneficial effect of erythromycin as a prokinetic agent [13-15]. Only one recent study demonstrated that low-dose oral erythromycin was effective in facilitating enteral feeding, decreasing the number of episodes of large gastric residuals and shortening the duration of parenteral nutrition, in preterm infants $>32$ weeks' gestation [16]. Nonetheless, no improvement was observed in infants with lower gestational ages. In contrast, all studies utilizing an intermediate or a high dose of oral erythromycin showed beneficial effects in promoting milk feedings and shortening the duration of parenteral nutrition requirements [17-19]. Additionally, the clinical outcome study has sufficient statistical power to demonstrate that use of erythromycin could reduce the incidence of PNAC by almost half (49\%) and with significantly fewer treated patients having abnormally raised serum alanine aminotransferase concentration [19]. The latter study also revealed a significant reduction in recur- 
Table 2. RCTs of erythromycin as a rescue prokinetic agent in preterm infants

\begin{tabular}{|c|c|c|c|}
\hline & ElHennawy et al. [13] & Ng et al. [14] & Cairns et al. [15] \\
\hline Purpose & rescue & rescue & rescue \\
\hline Sample size & 27 & 24 & 60 \\
\hline Inclusion criteria & $\begin{array}{l}29-36 \text { weeks' gestation; birth weight } \\
900-2,000 \text { g; failure to attain full enteral } \\
\text { feeding within } 8 \text { days of starting milk } \\
\text { feeds; presence of an intravenous line }\end{array}$ & $\begin{array}{l}\text { birth weight } \leq 1,500 \mathrm{~g} \text {; feed } \\
\text { intolerance with failure to start } \\
\text { non-nutritive enteral feeding by } 1 \\
\text { week or failure to attain } 20 \mathrm{ml} / \mathrm{kg} / \text { day } \\
\text { of milk feeds } 1 \text { week after commence- } \\
\text { ment }\end{array}$ & $\begin{array}{l}<37 \text { weeks' post-conceptional } \\
\text { age; failed within } 3 \text { or more days } \\
\text { to initiate or advance feeding }\end{array}$ \\
\hline Exclusion criteria & $\begin{array}{l}\text { sepsis within } 48 \text { h of study entry; } \\
\text { use of vasopressors or opioids; continuous } \\
\text { infusion feedings; } \\
\text { other conditions, including: NEC, } \\
\text { cardiac arrhythmia, intestinal myopathy, } \\
\text { hepatitis or liver failure, and congenital } \\
\text { or chromosomal abnormalities }\end{array}$ & $\begin{array}{l}\text { septicemia; major congenital } \\
\text { malformations; antenatal Doppler } \\
\text { documenting absent or reversed } \\
\text { end-diastolic flow }\end{array}$ & NEC; ileus \\
\hline \multicolumn{4}{|l|}{ Erythromycin usage } \\
\hline Dosage & low dose $(1.5 \mathrm{mg} / \mathrm{kg}$ every $6 \mathrm{~h})$ & low dose (5 mg/kg every $8 \mathrm{~h}$ ) & low dose ( 3 mg/kg every 6 h) \\
\hline $\begin{array}{l}\text { Duration } \\
\text { Route of administration }\end{array}$ & $\begin{array}{l}8 \text { days } \\
\text { oral }\end{array}$ & $\begin{array}{l}1 \text { week after full enteral feeding } \\
\text { oral }\end{array}$ & $\begin{array}{l}\text { until full enteral feeding } \\
\text { intravenous }\end{array}$ \\
\hline \multicolumn{4}{|l|}{ Results } \\
\hline $\begin{array}{l}\text { Age achieved full enteral feeding } \\
\text { after treatment: erythromycin vs. } \\
\text { placebo, days }\end{array}$ & $31 \pm 15$ vs. $36 \pm 16^{\mathrm{a}}$ & $24.9 \pm 2.9$ vs. $30.8 \pm 4.1^{* * *}$ & $13.0 \pm 14.1$ vs. $26.5 \pm 20.5$ \\
\hline Findings & no benefit & no benefit & no benefit \\
\hline Adverse effects & nil & nil & nil \\
\hline Comments & $\begin{array}{l}\text { - infants received erythromycin } \\
\text { emptied } 47 \pm 23 \% \text { of their feeding } \\
\text { in } 20 \text { min, whereas infants received } \\
\text { placebo emptied } 32 \pm 20 \% ; 70 \pm 20 \% \text { vs. } \\
64 \pm 26 \% \text { within one hour, respectively } \\
\text { - antroduodenal motor contractions were } \\
\text { similar in both groups }\end{array}$ & $\begin{array}{l}\text { - a higher proportion of infants in the } \\
\text { placebo group }(7 / 11,64 \%) \text { had } \\
\text { PNAC than those in the } \\
\text { erythromycin group }(4 / 13,31 \% ; \mathrm{p}= \\
0.11)\end{array}$ & $\begin{array}{l}\text { - post-hoc analysis suggested } \\
404 \text { infants would have been } \\
\text { needed to detect a mean } \\
\text { difference of } 3 \text { days; thus, the } \\
\text { benefits of low-dose } \\
\text { erythromycin are likely to be } \\
\text { modest }\end{array}$ \\
\hline
\end{tabular}

\footnotetext{
${ }^{\text {a }}$ Postnatal age achieved full enteral feeding (days).

Results are ${ }^{* *}$ median (interquartile range), mean (SD) or ** mean (SEM). None of the studies reported an increase in incidence of adverse effects associated with the use of erythromycin, e.g. infantile hypertrophic pyloric stenosis, cardiac dysrhythmia, sepsis and NEC.
}

rent septicemia, and that the use of the antimicrobial (high) dose of oral erythromycin did not promote the emergence of multidrug-resistant organisms during the prolonged investigation period (69 months) [19]. Interestingly, none of the studies reported a mean/median duration for achieving full enteral feeding that was longer in the erythromycin group than in the placebo group [10-
19]. The overall pattern suggested that the discrepancy of results between studies could have been related to the small sample size in some clinical trials $[13,14]$, as well as the different dosages used. It appears that in rescue therapy, the intermediate and high doses are probably more effective in stimulating the human GI tract and promoting milk feeding in preterm infants [17-19]. 


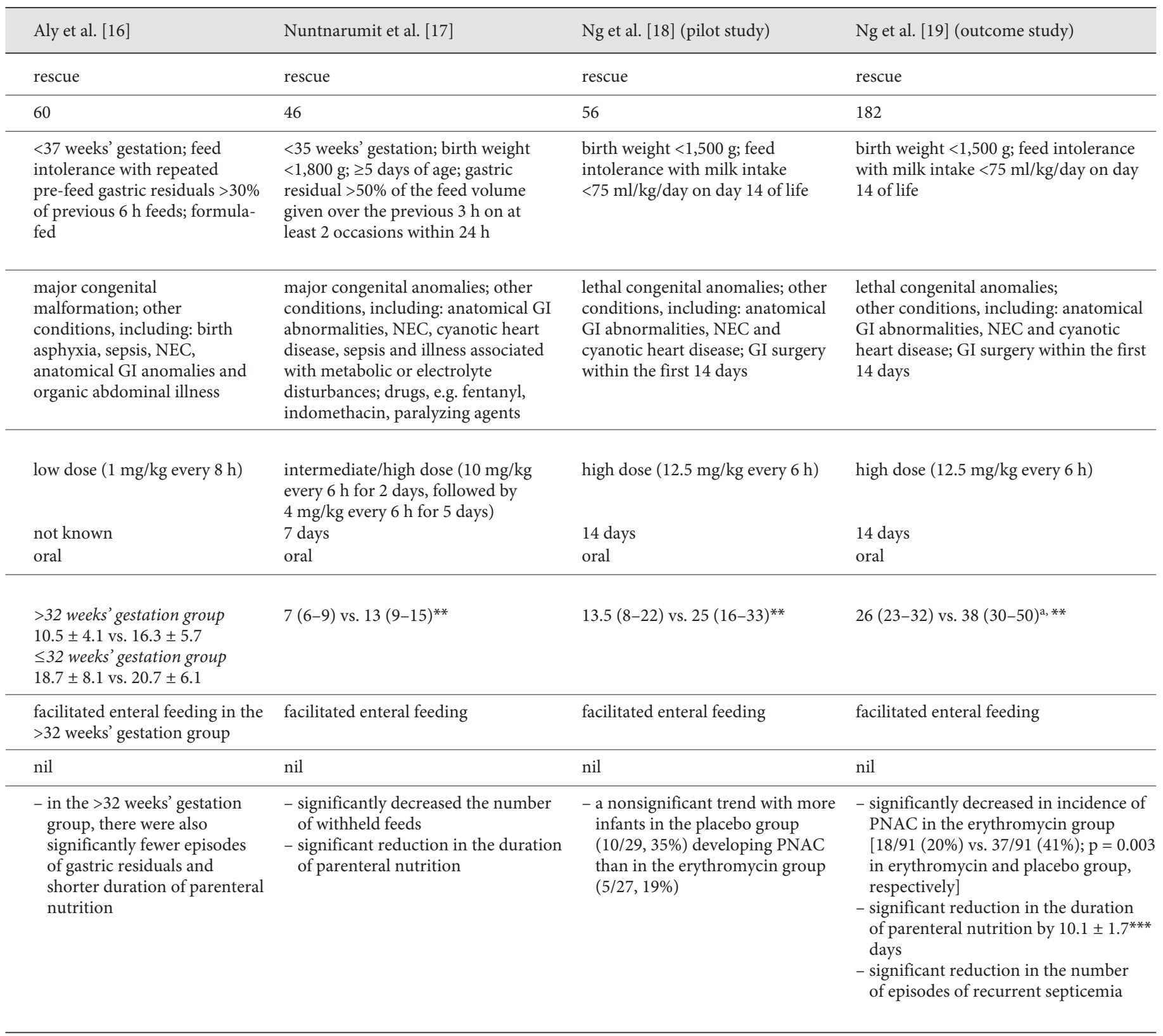

\section{Adverse Effects of Erythromycin in Preterm Infants}

None of the RCTs reported any major adverse effects associated with use of erythromycin [10-19]. In particular, infantile hypertrophic pyloric stenosis was not reported in any of the clinical trials [10-19]. The incidence of this complication is estimated to be $1-3$ cases per 1,000 live births in the Western population and administration of erythromycin will substantially increase the risk by 8 fold to 1 case per 41-125 treated infants [21]. With this prevalence, definitive cases should have been identified by the outcome study [19] or the combination of RCTs [10-19]. The fact that no cases have been identified suggests that the relationship between erythromycin and de- 
velopment of infantile hypertrophic pyloric stenosis is likely to be a weak association and the benefits of erythromycin probably outweigh any risk. Other sinister side effects of erythromycin, including: fatal cardiac arrhythmia, prolonged QTc intervals [18, 19], emergence of multidrug-resistant organisms [18, 19], outbreak of NEC and significant alteration of the pattern of stool microflora [19], have not been reported in these studies. In addition, the systematic review from The Cochrane Database on the use of erythromycin for prevention of chronic lung disease in intubated preterm infants at risk of Ureaplasma urealyticum infection did not indicate an increase in recognized adverse effects related to erythromycin [22].

\section{Mechanisms of Action}

The mechanism by which erythromycin enhances enteral feeding in preterm infants is not fully known. Current evidence suggests that its prokinetic action is mediated via the motilin pathway [23-25] and results in increasing proximal gastric tone [26], enhancing the strength and frequency of antral and proximal small bowel contractions [27-31] and reducing pyloric outlet resistance [24]. More importantly, recent studies have discovered 2 main types of motilin receptors [32]. The neural motilin receptor on cholingeric neurons is principally stimulated by low dose (1-3 $\mathrm{mg} / \mathrm{kg}$ ) erythromycin and can augment phase III migrating motor complexes, whilst the smooth muscle motilin receptor responds to higher doses and produces sustained antral contractions and promotes antroduodenal coordination $[25,30,33$, 34]. Although the lack of response to erythromycin in a proportion of preterm infants $<32$ weeks' gestation has been suggested to be associated with immaturity of the GI tract, results of recent RCTs suggest otherwise [17-19]. In fact, the development of the GI neuroendocrine network is almost complete by 25 weeks' gestation and it has been demonstrated that the distribution of motilin in the gut at 20 weeks' gestation closely resembles the pattern in adults $[35,36]$. Therefore, it appears that infants at very early gestations are already equipped with the essential physiologic and anatomic machinery necessary for normal functioning of the bowel.

Various human studies have provided important information about erythromycin as a potent prokinetic agent in preterm infants. Tomomasa et al. [37] used intravenous erythromycin $(0.75 \mathrm{mg} / \mathrm{kg})$ in preterm infants at 23-30 weeks' gestation and found a significant increase in antral cluster of contractions and 4-fold improvement in the antral motility index, signifying the presence of functional motilin receptors in the GI tract at very early gestations. In a closely related study, these investigators demonstrated that $10 \mathrm{mg}$ of oral erythromycin, but not a smaller dose $(3 \mathrm{mg})$, significantly increased the speed of gastric emptying [38]. Costalos et al. [34], in a crossover study, further suggested that oral erythromycin $(10 \mathrm{mg} /$ kg every $8 \mathrm{~h}$ ) enhanced antral contractility and increased the whole gut transit time measured by ultrasonography and the carmine red dye method. In contrast, Jadcherla and Berseth [39] using low-dose oral erythromycin (0.75$3 \mathrm{mg} / \mathrm{kg}$ ) failed to induce the phase III motor migrating complexes in infants $<31$ weeks' gestation but could successfully initiate stimulation of the bowel in a dosedependent fashion in infants $\geq 32$ weeks' gestation. ElHennawy et al. [13] failed to demonstrate that low-dose erythromycin $(1.5 \mathrm{mg} / \mathrm{kg})$ enhanced antroduodenal contractions or increase the GI transit time. Collectively, these data suggest that the action of erythromycin is probably dose and gestation dependent. As recent evidence indicates that the intermediate and high-dose erythromycin regimens are more effective than the lowdose regimen especially in clinical studies of rescue nature, we speculate that lower doses of erythromycin are probably insufficient to provide an adequate drug concentration necessary for exerting its desired prokinetic effects.

\section{Conclusions}

In the past decade, 10 RCTs have reported the effectiveness and adverse effects of erythromycin as a prokinetic agent in preterm infants [10-19]. The use of oral erythromycin is associated with a shorter time to attain full enteral feeding and may also decrease the duration of parenteral nutrition requirement [12, 17-19]. More importantly, the outcome study further indicates that the use of high dose oral erythromycin can reduce the incidence of PNAC by almost $50 \%$ and concurrently decreases the incidence of recurrent catheter-related septicemic episodes [19]. It is reassuring that none of the studies reported any major side effects, in particular, hypertrophic infantile pyloric stenosis and life-threatening cardiac dysrhythmia [10-19]. The current information probably favors the use of rescue rather than prophylactic treatment, intermediate to high doses rather than low-dose erythromycin and administering the medication intragastrically rather than intravenously, for the management of moderately severe functional GI dysmotility in 
preterm infants. Despite the apparent usefulness of erythromycin reported in some RCTs [12, 16-19], uncommon untoward effects, long-term effects on the bowel microflora and the possibility of promoting emergence of multidrug-resistant organisms in the neonatal intensive care unit, have not been fully evaluated. Thus, oral erythromycin should be used cautiously and selectively in preterm infants with moderately severe functional GI dysmotility and in whom a structural obstructive lesion has been excluded. This prokinetic agent should be most beneficial to infants receiving prolonged parenteral nutrition and thus at risk of developing PNAC. Future research should be directed to address unresolved issues in a multicenter RCT so that findings in the outcome study [19] can be validated, and also to confirm whether these beneficial effects are applicable to other ethnic populations. Therapeutic agents with motilinomimetric effects devoid of antimicrobial property should be further investigated $[40,41]$, as this category of drugs has the distinct advantage over erythromycin of not contributing to the emergence of resistant organisms.

\section{Financial Disclosure}

Research grants were awarded by the Research Grant Council of the Government of Hong Kong, SAR (project code: 4163/02M) and by the H.M. Lui Memorial Fund (project code: 6901814) for carrying out the oral erythromycin study in preterm infants.

\section{References}

1 Kaufman SS, Gondolesi GE, Fishbein TM: Parenteral nutrition associated liver disease. Semin Neonatal 2003;8:375-381.

$\checkmark 2$ Teitelbaum DH: Parenteral nutrition-associated cholestasis. Curr Opin Pediatr 1997;9: 270-275.

-3 Ng PC, Brownlee KG, Dear PRF: Gastroduodenal perforation in preterm babies treated with dexamethasone for bronchopulmonary dysplasia. Arch Dis Child 1991;66:11641166.

- 4 Ng PC, Fok TF, So KW, Wong W, Yip PK, Liu $\mathrm{K}$ : Lower gastrointestinal tract perforation in preterm infants treated with dexamethasone for bronchopulmonary dysplasia. Pediatr Surg Int 1997;12:211-212.

5 Stark AR, Carlo WA, Tyson JE, Papile LA, Wright LL, Shankaran S, Donovan EF, Oh W, Bauer CR, Saha S, Poole WK, Stoll BJ; National Institute of Child Health and Human Development Neonatal Research Network: Adverse effect of early dexamethasone in extremely-low-birth-weight infants. N Engl J Med 2001;344:95-101.

-6 Ng PC, Li K, Wong RPO, Chui KM, Wong E, Fok TF: Neutrophil CD64 expression: a sensitive diagnostic marker for late-onset nosocomial infection in very low birthweight infants. Pediatr Res 2002;51:296-303.

7 Kelly DA: Liver complications of pediatric parenteral nutrition: epidemiology. Nutrition 1998;14:153-157.

8 Andorsky DJ, Lund DP, Lillehei CW, Jaksic T, Dicanzio J, Richardson DS, Collier SB, Lo C, Duggan C: Nutritional and other postoperative management of neonates with short bowel syndrome correlates with clinical outcomes. J Pediatr 2001;139:27-33.

-9 Ng PC, Fok TF, Lee CH, Wong W, Cheung KL: Erythromycin treatment for gastrointestinal dysmotility in preterm infants. J Paediatr Child Health 1997;33:148-150.
10 Stenson BJ, Middlemist L, Lyon AJ: Influence of erythromycin on establishment of feeding in preterm infants: observations from a randomised controlled trial. Arch Dis Child Fetal Neonatal Ed 1998;79:F212F214.

11 Patole SK, Almonte R, Kadalraja R, Tuladhar R, Muller R, Whitehall JS: Can prophylactic oral erythromycin reduce time to full enteral feeds in preterm neonates? Int J Clin Pract 2000;54:504-508.

12 Oei J, Lui K: A placebo-controlled trial of low-dose erythromycin to promote feed tolerance in preterm infants. Acta Paediatr 2001;90:904-908.

13 ElHennawy AA, Sparks JW, Armentrout D, Huseby V, Berseth CL: Erythromycin fails to improve feeding outcome in feeding-intolerant preterm infants. J Pediatr Gastroenterol Nutr 2003;37:281-286.

14 Ng SC, Gomez JM, Rajadurai VS, Saw SM, Quak SH: Establishing enteral feeding in preterm infants with feeding intolerance: a randomized controlled study of low-dose erythromycin. J Pediatr Gastroenterol Nutr 2003;37:554-558.

15 Cairns P, Craig S, Tubman R, Roberts RS, Wilson J, Schmidt B: Randomised controlled trial of low-dose erythromycin in preterm infants with feed intolerance (abstract). Pediatr Res 2002;51:379A-380A.

-16 Aly H, Abdel-Hady H, Khashaba M, ElBadry N: Erythromycin and feeding intolerance in premature infants: a randomized trial. J Perinatol 2007;27:39-43.

17 Nuntnarumit P, Kiatchoosakun P, Tantiprapa W, Boonkasidecha S: Efficacy of oral erythromycin for treatment of feeding intolerance in preterm infants. J Pediatr 2006 148:600-605.
$18 \mathrm{Ng}$ PC, So KW, Fung KSC, Lee CH, Fok TF, Wong E, Wong W, Cheung KL, Cheng AFB: Randomised controlled study of oral erythromycin for treatment of gastrointestinal dysmotility in preterm infants. Arch Dis Child Fetal Neonatal Ed 2001;84:F177F182.

19 Ng PC, Lee CH, Wong SPS, Lam HS, Liu FYB, So KW, Lee CY, Fok TF: High-dose oral erythromycin decreased the incidence of parenteral nutrition-associated cholestasis in preterm infants. Gastroenterology 2007; 132:1726-1739.

$20 \mathrm{Ng} \mathrm{E}$, Shah V: Erythromycin for feeding intolerance in preterm infants. Cochrane Data System Rev 2001;2:CD001815.

- 21 Sørensen HT, Skriver MV, Pedersen L, Larsen H, Ebbesen F, Schønheyder HC: Risk of infantile hypertrophic pyloric stenosis after maternal postnatal use of macrolides. Scand J Infect Dis 2003;35:104-106.

22 Mabanta CG, Pryhuber GS, Weinberg GA, Phelps DL: Erythromycin for the prevention of chronic lung disease in intubated preterm infants at risk for, or colonized or infected with Ureaplasma urealyticum. Cochrane Data System Rev 2003;4:CD003744.

23 Jadcherla SR, Klee G, Berseth CL: Regulation of migrating motor complexes by motilin and pancreatic polypeptide in human infants. Pediatr Res 1997;42:365-369.

24 Mathis C, Malbert $\mathrm{CH}$ : Changes in pyloric resistance induced by erythromycin. Neurogastroenterol Motil 1998;10:131-138.

25 Coulie B, Tack J, Peeters T, Janssens J: Involvement of two different pathways in the motor effects of erythromycin on the gastric antrum in human. Gut 1998;43:395-400.

26 Varannes SBD, Parys V, Ropert A, Chayvialle JA, Roze C, Galmiche JP: Erythromycin enhances fasting and postprandial proximal gastric tone in humans. Gastroenterology 1995;109:32-39. 
-27 Jannssens J, Peeters T, Vantrappen G, Tack J, Urbain JL, De Roo M, Muls E, Bouillon R: Improvement of gastric emptying in diabetic gastroparesis by erythromycin. N Engl J Med 1990;322:1028-1031.

28 Holle GE, Steinbach E, Forth W: Effects of erythromycin in the dog upper gastrointestinal tract. Am J Physiol 1992;263:G52G59.

29 Otterson MF, Sarna SK: Gastrointestinal motor effects of erythromycin. Am J Physiol 1990;259:G355-G363.

-30 Tack J, Janssens J, Vantrappen G, Peeters T, Annese V, Depoortere I, Muls E, Bouillon R: Effect of erythromycin on gastric motility in controls and in diabetic gastroparesis. Gastroenterology 1992;103:72-79.

-31 Fraser R, Shearer T, Fuller J, Horowitz M, Dent J: Intravenous erythromycin overcomes small intestinal feedback on antral, pyloric, and duodenal motility. Gastroenterology 1992;103:114-119.
32 Parkman HP, Pagano AP, Vozzelli MA, Ryan JP: Gastrokinetic effects of erythromycin: myogenic and neurogenic mechanisms of action in rabbit stomach. Am J Physiol 1995; 269:G418-G426.

33 Annese V, Janssens J, Vantrappen G, Tack J, Peeters TL, Willemse P, Van Cutsem E: Erythromycin accelerates gastric emptying by inducing antral contractions and improved gastro-duodenal coordination. Gastroenterology 1992;102:823-828.

34 Costalos C, Gounaris A, Varhalama E, Kokori F, Alexiou N, Kolovou E: Erythromycin as a prokinetic agent preterm infants. J Pediatr Gastroenterol Nutr 2002;34:23-25.

35 Bisset WM, Watt JB, Rivers RPA, Milla PJ Ontogeny of fasting small intestinal motor activity in the human infant. Gut $1988 ; 29$ 483-488.

36 Berseth CL: Gestational evolution of small intestinal motility in preterm and term infants. J Pediatr 1989;115:646-651.

-37 Tomomasa T, Miyazaki M, Koizumi T, Kuroume T: Erythromycin increases gastric antral motility in human premature infants. Biol Neonate 1993;63:349-352.
38 Tomomasa T, Tabata M, Nako Y, Kaneko H, Morikawa A: The effect of oral erythromycin on gastric emptying in neonates with gastric retention (abstract). Gastroenterology 1997; 112(suppl):A839.

39 Jadcherla SR, Berseth CL: Effect of erythromycin on gastroduodenal contractile activity in developing neonates. J Pediatr Gastroenterol Nutr 2002;34:16-22.

40 Verhagen MAMT, Samsom M, Maes B, Geypens BJ, Ghoos YF, Smout AJ: Effects of new motilide, ABT-229, on gastric emptying and post-prandial antroduodenal motility in healthy volunteers. Aliment Pharmacol Ther 1997;11:1077-1086.

41 Nieuenhuijs VB, van Duijvenbode-Beumer H, Verheem A, Visser MR, Verhoef J, Gooszen HG, Akkermans LM: The effects of ABT-229 and octreotide on interdigestive small bowel motility, bacterial overgrowth and bacterial translocation in rats. Eur J Clin Invest 1999;29:33-40. 